\title{
EXPERIENCE AND REFLECTION: CURRICULUM UNITS TO DEVELOP GENERIC SKILLS IN SPEECH AND LANGUAGE THERAPY STUDENTS
}

\author{
Helena Germano, Joaquim Gronita \\ Instituto Politécnico de Setúbal - Escola Superior de Saúde (PORTUGAL)
}

\begin{abstract}
The Speech and Language Therapy (SLT) program held at Instituto Politécnico de Setúbal, Portugal, integrates a domain of personal and professional development since the implementation of Bologna process. This domain includes nine curriculum units named Experience and Reflection (ER), with 54 hours each (25 contact hours). ER intends to develop generic competences allowing students to integrate forms of relationship relevant for the clinical dimension of SLT and to know how to avoid risk situations for themselves and others.
\end{abstract}

The purpose of this study is to investigate how the SLT students perceive the relevance of ER in the curriculum and whereas the target competences are tuned with the European standards.

Method: In this study participate 55 students, enrolled in ER IX in three different academic years: 2012 (14 students), 2014 (18 students) and 2016 (25 students). All the students attended all nine ER included in their academic route. In 2012, students performed a reflection focusing on the topics: relevance of ER in the academic curriculum, what did it represented to them, which competences were fully developed and which were still under development. In 2014, students filled in a selfassessment questionnaire based on the generic competences defined by NetQues ${ }^{[1]}$, using a Likert scale from 1 to 5 , where $1=$ not acquired and $5=$ completely acquired. In 2016, students reply to the 2014 questionnaire, and performed a reflection on the same three topics as in 2012. A thematic analysis of the qualitative data was performed, and the results of the questionnaire were analyzed.

Results: Thematic analysis of the reflections on both years allowed identifying 6 themes: (In)Comprehension of the purpose of ER; Preparing for professional practice; Personal development and self-knowledge; Pedagogical Methodologies; Final balance; Suggestions. The results of the questionnaire where very similar in both 2014 and 1016, therefore were analyzed together. The average value of self-assessment varied between 4,0 and 4,8 , which means that students considered generic competences as acquired.

Conclusion: This study identified aspects to improve in the ER curriculum and it was possible to conclude that students considered ER relevant in the curriculum of the SLT course and they achieved the target generic competences, being at the level of European standards for a newly qualified SLT.

Keywords: Experience, Reflection, Generic skills, Personal and professional development.

\section{INTRODUCTION}

The Speech and Language Therapy (SLT) program held at Instituto Politécnico de Setúbal, Portugal, integrates a domain of personal and professional development since the implementation of Bologna process. In this paradigm, it appears that the student is determined to define what to do, and how to select and evaluate appropriate resources to do it. This framework requires that the students, in order to be succeeded, must learn how to regulate, organize and empower themselves. Furthermore, it aims to catalyze a maturation process of the student, enabling him to integrate forms of relation inherent to the clinical dimension of speech therapy and to the therapist action.

This personal and professional development curriculum domain includes nine curriculum units (CU) named Experience and Reflection (ER), with 54 hours each (25 contact hours). The inclusion of this domain aims the work of the students on their own needs as people and future professionals. It includes skills related to identification of their own needs, identification of characteristics of their own profile, awareness of the consequences of the characteristics identified to their action as future professionals, searching for information and identification of pathways for professional development. Accordingly, ER intends to develop generic competences - intrapersonal and interpersonal 
competences - allowing students to integrate forms of relationship relevant for the clinical dimension of SLT and to know how to avoid risk situations for themselves and others.

When these CU were designed, back in 2008, stemmed from a theoretical framework that included the concepts of: Intrapersonal and interpersonal intelligence (Gardner, 1983) ${ }^{[2]}$; Empowerment in education - critical thinking (Harvey, 2004) ${ }^{[3]}$; Reflection (Law, Ireland \& Hussein, 2007) ${ }^{[4]}$; Tutoring and Mentoring; Double loop learning (Brockbank \& McGill, 2006) ${ }^{[5]}$.

Interpersonal intelligence allows the individual to act and react with others correctly and adaptively. It leads to finding the differences and nuances of temperament, character and reasons for action among people. It allows empathy, cooperation and tolerance. Facilitates the detection of the intentions without them being expressed. This intelligence facilitates the resolution of problems linked to relationships with others and enables to understand and generate valuable solutions to help them. ${ }^{[2]}$ Intrapersonal intelligence is the capacity that the subject has to decipher their emotions and maintain openness to their needs and desires. It allows the anticipation by the subject of his behavior and leads to a good understanding and knowledge of self. ${ }^{[2]}$ Both are at the heart of relational competence required in the therapeutic process and counseling.

The theoretical perspective of intelligence that is suggested considers the subject as having potential multiple resources that the teaching / learning process will lead to a balanced update, consistent with the objectives which he proposed himself.

The convergence of this theoretical perspective and the educational purposes of ER determine to define the process that will allow achieving the intended purpose.

Such process encompasses the concept of empowerment. Empowerment in education includes variables such as control of their own destiny, increase of knowledge, participation in decision making, enable the other, provide resources, take responsibility, dignity and respect (Bartunek, J. e Spreitzer, G., 2006) ${ }^{[6]}$. We adopted the perspective of Harvey $(2004)^{[3]}$, which states that one of the ways to generate empowerment in university students is to develop their critical thinking, or metacognition. Students are encouraged to think about knowledge as a process in which they are involved. Metacognition requires students to self-assess, to be able to assess how good their work is and when did they achieve it. It enables students to apply what they find beyond the school.

In order to operationalize this process, we choose to adopt the model of single and double loop learning ${ }^{[5]}$. It represents a transformational learning process. Single loop learning integrates four moments: experience, reflection, generalization and testing. Double loop learning represents a paradigm shift which happens after the reflection moment, displacing the dynamic process to a new moment of emerging knowledge, inside which the single loop can happen again.

Reflection is a significant element in the learning process, whereas it is a process of translating the experience in significant concepts, implying thought and feeling, which leads to the emergence of a new appreciation, understanding and insight for this experience ${ }^{[4]}$.

$E R$, as the name shows, promotes experiences and requires students to reflect about. Firstly, a classroom interpersonal reflection is taken as reflective dialogue that challenges the participants, promoting the transformational learning. Secondly, an intrapersonal written reflection would consolidate the learning experience and promote self-knowledge.

The main competences that ER deploys are: self-knowledge and self-realization, resilience, assertivity, emotional competence, time management, cooperation, clinical relationship, networking, creativity, diversity management and management of changing situations.

Pedagogical strategies adopted to achieve these goals are group teaching (lectures, debates), model observation, role-playing, constructive feedback, diary, generalization activities (Jardim \& Pereira, 2006) $)^{[7]}$

ER is embedded in the curriculum mostly in the first two years: ER I to IV in the first year, ER V to VIII in the second year and ER IX at the end of the fourth year.

The contents of the nine ER are organized as follows: ER I - How to make a reflection (Gibbs model); Stress self-assessment, coping strategies; Time management. ER II - Interpersonal communication; Clinical entreview. ER III - Diversity: elderly, gender, handicap. ER IV - Multiculturality; Lay knowledge in SLT. ER V - Team work. ER VI - Work with children ; Work settings ; Waiting room; ER VII - Work with families ; Protocol to give bad news; ER VIII - First observational internship - bridging all ER's. 
ER IX - Analysis of the student's pathway since the first year and future perspectives as a speech therapist.

The purpose of this study is to investigate how the SLT students perceive the relevance of ER in the curriculum and whereas the target competences are tuned with the European standards.

\section{METHODS}

\subsection{Participants}

In this study participate 55 students, all females, enrolled in ER IX in three different academic years: 2012 (14 students), 2014 (18 students) and 2016 (25 students). All the students attended all nine ER included in their academic route. The mean age of participants is 22 years old.

\subsection{Procedures}

The first group of students that had attended all nine ER concluded in 2012, It was decided to perform an assessment about their perception of this set of CU with this first sample of students. The 14 students were asked to write a free reflection about relevance of ER in the academic curriculum, what did it represented to them, which competences were fully developed and which were still under development.

In 2014, "key subject specific and generic competences which form common standards for European SLT initial education" (NetQues-CPLOL, 2013) was recently published; we adapted the 25 generic competences to a self-assessment questionnaire using a Likert scale from 1 to 5 , where $1=$ not acquired and 5=completely acquired. Eighteen students filled the questionnaire online on Google forms.

During 2016 the curriculum has been under revision. In order to gather more qualitative information from the students, we choose to apply 2014 questionnaire, and to ask them to write a reflection on the same three topics as in 2012.

Qualitative data of each year was analyzed following the methodology of Thematic Analysis (Braun \& Clarke, 2006) ${ }^{[8]}$.

The results of the questionnaire where analyzed using Excel and the answers from both years where compared.

\subsection{Questionnaire}

The questionnaire on generic competences was divided in three sections: Interpersonal and Intrapersonal Competences, Systemic Competences and Instrumental Competences. The questions presented were, for the Interpersonal and Intrapersonal Competences: 1. Demonstrate a behavior which is honest, sincere and reliable. 2. Demonstrate empathy with clients and colleagues. 3. Extract information from informants efficiently and sympathetically. 4. Provide accurate feedback in a comprehensible and sensitive manner. 5. Demonstrate advanced social skills such as assertiveness, cooperation, negotiation. 6. Appreciate diversity and multiculturalism. 7. Show positive attitude and pro activeness. 8. Be self-critical and reflect on their own performances. 9. Demonstrate resilience in coping with the demand of the profession in a way which enables him/her to maintain self-esteem and manage stress; for the Systemic Competences: 10. Take responsibility for developing his/her own knowledge and skills throughout his/her lifespan. 11. Work independently and autonomously. 12. Adapt his/her own behavior and approach to fit new situations. 13. Formulate creative and original solutions for novel situations. 14. Conduct a search of the scientific literature to find the most relevant information to answer a question; finally, for the Instrumental Competences: 15. Use appropriate, effective skills and materials in written, oral and visual communication of information and instruction. 16. Gather data using various methods including literature review, interviewing, questionnaire and observation. 17. Identify the important factor in a problem and suggest possible solutions. 18. Express the preferred solution/decision in a comprehensible way and outline the concrete actions required. 19. Identify the risks or pitfalls associated with each possible solution. 20 . Use this knowledge to select the most appropriate solution for the particular circumstances. 21. Analyze information to draw appropriate conclusions and recognize the implications of these conclusions. 22. Synthesize information from diverse sources to select an appropriate course of action or to answer a question. 23. Apply legal and ethical principles in managing information and protect integrity, reliability and authenticity of records. 
24. Divide tasks into concrete steps and set time schedules with realistic aims, taking into account all other demands. 25. Meet goals or deliver products of work on schedule.

\section{RESULTS}

\subsection{Thematic analysis}

The thematic analysis of the reflections on both years allowed identifying 6 themes:

(In)Comprehension of the purpose of ER; Preparing for professional practice; Personal development and self-knowledge; Pedagogical Methodologies; Final balance; Suggestions. We bring the analysis results herein.

\subsection{1 (In)Comprehension of the purpose of ER}

Most of the students refer to don't understand completely the meaning and the importance of ER during the two first years, because it was not focused on the speech therapy core subjects. However, they all admit that it was during the first clinical internship, when they had to do therapy with real clients, that they could understand the applicability of all subjects worked in ER.

Initially, during the first two years of course, I did not realize the utility of it. Presently I already understand the usefulness of experience and reflection and its importance for the training of future speech therapists. This shift in thinking is related to the experiences I had on internship context, which put into practice many of the skills learned over all units of experience and reflection. [MR, 11/12].

I didn't see great benefit in what they were proposing, and I supposed they were asking me to work on something related to psychology. This feeling still remained for some time. Then I realized that this content would be an asset in the future, but it was when started my first internship that I understood how important was the content covered in these CUs for the construction of my "professional self." [JM, 15/16]

\subsubsection{Preparing for professional practice}

Students highlighted importance of ER to prepare professional practice, underlining two main subthemes: the internships and the future professional practice.

It was considered by students that preparation for professional practice during classes results from the confrontation with many critical situations which allowed them to act in a safe context and to address that action towards the acquisition of interpersonal relationship competences with the clients, both in the internship and future professional practice.

It is very important to know all these strategies and attitudes to either adopt or avoid as speech therapists in order to pay a quality service to our clients. [MR, 11/12]

The fact that, in an informal context, I have experienced certain situations and have already thought about them and how to handle it, allowed me to anticipate behaviors and plan more effectively an appropriate response, resulting in better performance in practice. [AZ, 11/12]

Regarding the future applicability of the skills developed in these CU's, I believe that both theoretical learning and self-analysis and self-reflection skills will be valuable tools I will take to my professional life, because I think there will always be room to improve and to grow, and that this can only happen when applying to such aspects." [RO, 15/16]

\subsubsection{Personal development and self-knowledge}

Many students consider that ER had an impact on their own personal lives and that impact was transferred to the professional field. In their reflections there is a strong component of explicit selfknowledge and self-assessment, recognizing aspects of the self that has changed or still must be changed in order to be a better person and a better professional.

I felt that my personal life was what first suffered the impact of what I've learned. Only afterward this has been transposed into my professional life." [NS, 11/12]

These courses (...) contributed as well to our personal and relational development. They helped us to "create" an identity. We had no pressure to do it right, nor would it be the goal and would 
not even be possible. The goal was to overcome our fears, our difficulties and learn. It made us reflect deeply about ourselves, about our journey, and, in the end, about life. I think this "touched" us, it was like "shaking" us. So I describe all UC as something that "shook" us to change. [PC, 11/12]

I think that [ER] helped me to be a better person, having more weighted attitudes, to think more before acting, thinking more about the other; and, mostly important too, to better accept differences and have a broader view of society in which we live today, and about the stereotypes I create myself as well. [MA, 15/16]

The ability and courage to think about me has allowed me to recognize my skills and failures, and hence identify courses of action to operationalize positive changes. Think about us and gain greater self-knowledge is a continuous process, hard, but precious. [MS, 11/12]

My performance in some of the courses in question was fair, which now causes me some regret, mostly because now I realize how important were the topics for clinical practice [MSi $15 / 16]$

\subsubsection{Pedagogical Methodologies}

This theme has two sub-themes: Role-play and Reflection.

Students refer spontaneously in their reflections the most salient aspects of the pedagogical methodology adopted in ER. Generally, they refer the good dynamics of classes, the good balance between theory and practice, and how the proximity teacher/ student acted as facilitator of the learning process.

Classes were dynamic, allowing the interaction between students and teachers, encouraging the development of communication skills and also providing a discussion of the various points of view, thus enriching our knowledge.[SP, 15/16]

In the sub-themes, we can find a difference between the students of the year 2011/12 and the year 2015/16. Students from 2011/12 talked often about the role-play and none refers to reflection, and the opposite occurs in 2015/16 students, who were mostly focused on the reflection process.

The reason for this to happen can be related to the fact that reflections where asked the 2011/12 students as assignments, but by then the Gibbs model of reflection had not yet been adopted. Students could reflect as they wish, without guidelines for thinking, i.e., their reflection process was easier. Reading these reflections, we found that students needed a model to help them organize thinking, which we adopted, starting using the Gibbs model for the courses from the following years and on. However, this model was not consensually accepted by the students, as we can see from some of his comments, while acknowledging the importance of reflection as a development promoter.

Initially it did not make much sense to me to use a model to reflect on what I thought. However, this model has become an asset in this reflective process, significantly helping to structure my ideas. (...) I did not understand the importance of reflections, but throughout my academic career I realized that reflection is more about learning than an assessment element. [AV, 15/16]

The reflections tend to be a bit dull and lose their sense, making it difficult to acquire skills with them. [BO, 15/16]

Personally, I greatly cherish the exercise done throughout these CU's, i.e., the exercise of reflection and, above all, self-reflection. First, because I consider extremely important to cultivate the reflection on relevant themes and issues, whether it be personal, professional, social, civic, moral, relational, etc. The reflection often allows a mindful change of the detected problems, and it is in this reflective exercise that we can identify problems, errors, aspects to improve in a perspective that crosses different spheres intentionally; so I think the reflective approach is always a "richer" approach when compared to other. This reflective capacity is important for the professional self, but also for me as a person, having an opinion and being an active member in the micro and macro society, which enables my development and my personal and professional growth and promotes a self-differentiation. [RO, 15/16]

Role-play is either loved or hated, depending mostly on the more or less extroverted temperament of students. But its importance as a simulation of plausible situations that can occur in professional practice is recognized by all the students that mentioned it. 
Experience and Reflection classes were a constant challenge. Having to put myself in the roleplay situations meant facing fears. However, in the end I thought it to be not so bed and could face my performance as something positive and developing. [AZ, 11/12]

Role-play allows us a little experience of what might arise in the future, and the work done on skills can be adapted / suitable for other situations. [AF, 11/12].

The way some classes were held through role-play was not my favorite. Moreover, I never liked that kind of exposure, nor I ever had any talent to act or felt myself at ease doing it. That's that very reason why I would feel diminish or penalized in relation to my colleagues who liked this methodology.[MA, 15/16]

\subsubsection{Final balance}

In their conclusions of the reflections, students made a final balance of ER, referring the pertinence of these CU for the curriculum, which contribute, in their perspective, to differentiate them from students of other schools and to better prepare them as health professionals sensitive to their client, multicultural aware, capable to team-work and skilled to establish therapeutic relationships which enable them to empower others.

The need to develop these skills to provide the best possible care to the client justifies the relevance of ER in the curriculum of the Speech Therapy course. [MS, 11/12]

Experience and Reflection is what distinguishes IPS School of Health Sciences from the other schools with the SLT course. [AG, 11/12]

We cannot forget we are there to take care of others. And we can only establish a fully helpful relationship if we ourselves feel understood and supported. ER represents that same understanding and support. Everything we've learned can be applied to practice, becoming these CU extremely useful to the professional practice of a SLT. I consider ER as the most important CU of our academic curriculum. [PC, 11/12\}

I realized that all ER contributed in some way to my performance as a student, as an intern, and certainly as a speech therapist. [IR, 11/12]

\subsubsection{Suggestions}

Many students gave constructive feedback to help us to improve ER. There was only one of the students who just criticized negatively.

The 2012' students presented their opinions and gave suggestions having in mind that they were the first group having ER. They found some subjects repetitive, as time management or therapeutic relationship, and suggested to focus as well on teamwork and conflict management (especially as a preparation for the internship and for the sensitive relationship with their clinical supervisor), creativity and art expressions.

Many of these suggestions were introduced in the new releases of the ER, and the structure of each ER developed a more specific identity.

The 2016 students refer to need more written feedback from teachers, and more demonstrations (videos, testimonials), in order to better understand the relevance of the subjects and how to act.

We can consider this constructive feedback given by the students a good result of these $\mathrm{CU}$, as students are empowering us to do better.

\subsection{Results of the Questionnaire}

The results of the questionnaire where very similar in both 2014 and 1016, therefore were analyzed together.

The average value of self-assessment varied between 4,0 and 4,8 , which means that students considered generic competences as acquired. The lowest result came in question 9 (stress management and resilience), with an average of 4,0, and, in questions 13, 17, 18, 19, 20, (problem solving and decision making) with an average of 4,1 .

The highest results came in question 1, with the average of 4,8 , and in questions $2,6,7$ and 10 , with an average of 4,7 . 


\section{DISCUSSION AND CONCLUSION}

Following the analysis of the 2012 reflections, it was clear students had initial difficulties to understand the objectives of ER. Since then, transparence was improved by presenting the objectives in the first class of each ER, as well as the intended learning outcomes and assessment methodologies. That information became also available on the School website. Thus, when in 2016 we got similar difficulties it was puzzling. It will be required extra research efforts to understand how students create these initial representations of ER and how it stands throughout the years.

In their reflections, students considered intrapersonal and interpersonal competences important and that in most of the cases they were achieved. However, by the way the questionnaire was answered we can see the existence of a slight fragility in the self-assessment of stress management and resilience. One possible justification for these results can be the fact that $4^{\text {th }}$ year students are dealing with more pressure than usual, considering they are finishing their research work and preparing its public presentation, as well as they feel very close to the moment of searching for a job. These circumstances are stressful and possibly contribute to a contamination effect onto the questionnaire was answered. Nevertheless, it is important to consider to include a new module on coping strategies in ER IX. It can be useful to help students achieving a feeling of control under pressure.

On both groups, the good quality of self-assessment and self-knowledge mirrored on reflections contrasts with student's opinion about the elaboration of reflective assignments. Students learned how to reflect, but they are not fully aware of their competence to do it, focusing in the difficulty of the process. The extra need of feedback from the teachers, which they also refer, can be an explanation. A more efficient way to give feedback to students would have to be analyzed.

The answers to the questionnaire show that students feel less secure on their instrumental competences on problem-solving. A problem-solving model is worked with them in ER I and II, and they are encouraged to apply it on the final steps of the Gibbs model of reflection, when they have to identify needs of change and to define an action course to improve such change. By reading reflections along the years, we had found before that difficulty, which get confirmation from the questionnaire results. We conclude that problem solving and decision making subjects require further investment and need to be bridged to other CU besides ER, requiring a closer teamwork of teachers working on curriculum development.

During the current process of SLT curriculum revision, the results of this study will be considered to improve curriculum quality and to improve professional competences of future speech and language therapists in Portugal.

In conclusion, students considered ER relevant in the curriculum of the SLT course and that they achieved the target generic competences, being at the level of European standards for a newly qualified SLT.

\section{REFERENCES}

[1] CPLOL (2013). NetQues Project Report. Speech and Language Therapy Education in Europe. United in Diversity. Retrieved in 2013 from http://www.netques.eu/wpcontent/uploads/2013/10/NetQues Project_Report_SLT_Education in Europe_260913.pdf

[2] Gardner, H. (1995). Inteligências múltiplas. A teoria na prática. Porto Alegre: Artmed Editora.

[3] Harvey, L. (2004). Analytic Quality Glossary. Quality Research International. Retrived in 2008 from http://www.qualityresearchinternational.com/glossary/empowerment.htm.

[4] Law, H., Ireland, S., Hussain, Z. (2007). The psychology of coaching, mentoring and learning. UK: John Wiley \& Sons.

[5] Brockbank, A., McGill, I. (2006). Facilitating reflective learning through mentoring \& coaching. London: Kogan Page.

[6] Bartunek, J., Spreitzer G. (2006). The interdisciplinary career of a popular construct used in management: Empowerment in the late 20th Century. Journal of Managment Inquiry.15, 3 ABI/INFORM Global. Retrieved in 2008 from http://jmi.sagepub.com/cgi/content/abstract/15/3/255

[7] Jardim, J., Pereira, A. (2006). Competências pessoais e sociais: Guia prático para a mudança positiva. Porto: ASA Editores. 
[8] Braun, V., Clarke, V. (2006). Using thematic analysis in Psychology. Qualitative Research in Psychology, 3: 77-101. 